\title{
Article \\ Impact of Seasonal Variation and Processing Methods on the Cassava-Derived Dietary Cyanide Poisoning, Nutritional Status, and Konzo Appearance in South-Kivu, Eastern D.R. Congo
}

\author{
Marius Baguma ${ }^{1,2,3, * \mathbb{D}}$, Christiane Migabo ${ }^{4,5} \mathbb{D}$, Fabrice Nzabara ${ }^{1}$, Wany Linda Sami ${ }^{1} \mathbb{D}$, \\ Christian Manegabe Akili ${ }^{1}$, Samuel Makali Lwamushi ${ }^{1,6}{ }^{(D}$, Jules Mufungizi Bisimwa ${ }^{7}$, Aimé Nkemba ${ }^{8}$, \\ Pacifique Chirhalwirwa ${ }^{9}$, Ghislain Balemba Maheshe ${ }^{1,6} \mathbb{D}^{\mathbb{D}}$, Jean-Michel Rigo ${ }^{2} \mathbb{D}$ and Joëlle Nsimire Chabwine ${ }^{1,10}$
}

check for

updates

Citation: Baguma, M.; Migabo, C.; Nzabara, F.; Sami, W.L.; Akili, C.M.; Makali Lwamushi, S.; Bisimwa, J.M.; Nkemba, A.; Chirhalwirwa, P.; Maheshe, G.B.; et al. Impact of Seasonal Variation and Processing Methods on the Cassava-Derived Dietary Cyanide Poisoning, Nutritional Status, and Konzo Appearance in South-Kivu, Eastern D.R. Congo. Processes 2022, 10, 337. https://doi.org/10.3390/pr10020337

Academic Editors: Ángeles Alonso-Moraga and Mercedes Del Río Celestino

Received: 23 January 2022 Accepted: 8 February 2022 Published: 10 February 2022

Publisher's Note: MDPI stays neutral with regard to jurisdictional claims in published maps and institutional affiliations.

Copyright: (C) 2022 by the authors. Licensee MDPI, Basel, Switzerland. This article is an open access article distributed under the terms and conditions of the Creative Commons Attribution (CC BY) license (https:// creativecommons.org/licenses/by/ $4.0 /)$.
1 Department of Internal Medicine, Hôpital Provincial Général de Référence de Bukavu, Université Catholique de Bukavu (UCB), Bukavu P.O. Box 285, The Democratic Republic of the Congo; fabricenzabara@gmail.com (F.N.); samiwany@outlook.com (W.L.S.); simplicearc@gmail.com (C.M.A.); maheshe.balemba@ucbukavu.ac.cd (G.B.M.); samuelmakali11@gmail.com (S.M.L.); joelle.chabwine@unifr.ch (J.N.C.)

2 Biomedical Research Institute (BIOMED), Faculty of Health and Life Sciences, UHasselt-Hasselt University, 3590 Diepenbeek, Belgium; jeanmichel.rigo@uhasselt.be

3 Center for Tropical Diseases and Global Health (CTDGH), Université Catholique de Bukavu (UCB), Bukavu P.O. Box 285, The Democratic Republic of the Congo

4 Faculty of Agronomy, Université Catholique de Bukavu (UCB), Bukavu P.O. Box 285, The Democratic Republic of the Congo; migabo.nabintu1@ucbukavu.ac.cd

5 Department of Geography and Environmental Studies, College of Social Sciences and Humanities, Jimma University, Jimma P.O. Box 378, Ethiopia

6 École Régionale de Santé Publique (ERSP), Université Catholique de Bukavu (UCB), Bukavu P.O. Box 285, The Democratic Republic of the Congo

7 Mwana Heath Zone, Mwenga, Bukavu P.O. Box 162, The Democratic Republic of the Congo; jules1bisimwa@gmail.com

8 Idjwi Heath Zone, South-Idjwi, Bukavu P.O. Box 162, The Democratic Republic of the Congo aimenkemba2@gmail.com

9 Monvu General Hospital, Monvu, South-Idjwi, Bukavu P.O. Box 162, The Democratic Republic of the Congo pchirhal74@gmail.com

10 Neurology Unit, Department of Neuroscience and Movement Science, Faculty of Science and Medicine, University of Fribourg, 1700 Fribourg, Switzerland

* Correspondence: baguma.akonkwa@ucbukavu.ac.cd

Abstract: This study aimed at evaluating the impact of seasons on the nutritional status and on dietary cassava-related cyanide exposure in Burhinyi and Idjwi, two areas in the eastern Democratic Republic of the Congo, witnessing similarly high cassava-derived cyanide poisoning but differently affected by konzo and malnutrition. Cyanide content in cassava roots and flour, and urinary thiocyanate levels (uSCN) of 54 subjects (40 from Burhinyi and 14 from Idjwi, aged 28.7 (12.1) years, 63\% women) were measured during the rainy season (RS) and dry season (DS), using picrate paper kits A and D1. Local processing methods proved to be efficient in removing cyanogenic compounds in fresh cassava roots during the RS. However, the cyanide content in flour samples significantly increased during DS, with $\sim 50 \%$ of samples containing unsafe levels (>10 ppm) of cyanide content. Strikingly, the uSCN ( $\mu \mathrm{mol} / \mathrm{L})$, from being comparably high in RS ( 172.0), slightly decreased during DS in Burhinyi ( 103.2; $p=0,3547)$, but not in Idjwi $(\sim 172 ; p=0,1113)$. Furthermore, serum proteins and albumin levels significantly decreased during the DS, witnessing a worsening of nutritional status, in Burhinyi but not in Idjwi. The consumption of bitter cassava roots $(\mathrm{OR}=5.43, p=0.0144)$ and skipping heap fermentation $(\mathrm{OR}=16.67, p=0.0021)$ were independently associated with very high uSCN levels during the DS. Thus, restoring the traditional processing methods, and complying with them in either season should ensure the safe consumption of cassava.

Keywords: cassava toxicity; cyanide poisoning; processing methods; seasonal variation; nutritional status; konzo 


\section{Introduction}

Cassava (Manihot esculenta Crantz) is a tropical plant, of which the root constitutes a major source of calories and a staple food for about 800 million people worldwide, mainly residing in tropical countries [1]. It is the most produced staple food in Africa and the fourth most important crop worldwide, after maize, wheat and rice [2,3]. Cassava is an excellent reserve crop against famine, highly appreciated among subsistence farmers in sub-Saharan African countries as a rich source of carbohydrates and owing to its easy adaptation to poor soils $[1,4,5]$. However, cassava roots have very low protein content [6] and hold potentially toxic cyanogenic glucosides (mainly linamarin and a small amount of lotaustralin) at various concentrations [7].

Total cyanogenic glucosides concentration in cassava roots, while determining the latter's taste [8], depends on cultivar varieties, environmental conditions, cultural practices, and on the age of the plant [9]. Cyanogenic glucosides allow plant survival in harsh environmental conditions and are protective against predators' attacks and pests $[8,10]$. However, their degradation leads to the release of cyanide, one of the most powerful poisons for human beings [11]. Cassava varieties are classified as "sweet" or "bitter", as they contain respectively $<50$ or $>50 \mathrm{ppm}$ (ppm refers to cyanide equivalents in milligrams per kilogram of cassava on a fresh weight basis) [12]. Bitter varieties are considered to be toxic and require, prior to ingestion, efficient processing for cyanogenic compound removal $[13,14]$ below the safety level set by the Food and Agriculture Organization (FAO) and the World Health Organization (WHO) at $\leq 10$ ppm [15].

When properly processed, cassava remains a safe food. Various traditional processing methods for cassava products (such as water soaking or heap fermentation) have proved to be efficient in reducing cyanide content below the toxic threshold [16], as witnessed by rare cases of acute cyanide intoxication from cassava products noticed in populations regularly consuming cassava [11]. However, in periods of severe food deprivation (e.g., adverse climatic events such as drought, war, and other humanitarian disasters), some communities do not comply with their usual (somehow time-requiring) processing. Thus, they either resort to inefficient methods (such as sun drying alone) or introduce shortcuts to their traditional processing, which results in high (toxic) residual cyanogen content in processed cassava species [17-19].

Chronic ingestion of unproperly processed (toxic) cassava products is associated with a number of disorders, among which include malnutrition, pancreatitis, thyroid dysfunction, and neurological diseases (e.g., tropical ataxic neuropathy and konzo) [16,20,21]. Thus, the appropriateness of cassava processing constitutes a key element to ensure the safe consumption of cassava products [22], which contributes to prevent the above-mentioned pathological conditions, especially konzo [23]. Konzo is a crippling neurological disease characterized by a spastic non-progressive paraparesis (or tetraparesis in severely diseased patients) of abrupt onset and irreversible course [20,24], affecting poor African communities under severe food deprivation conditions and predominantly consuming toxic cassava $[18,20]$.

The former Bandundu province, in the western part of the Democratic Republic of the Congo (DRC), constitutes the major focus of konzo worldwide, accounting for more than half of all konzo cases and reported epidemics [20]. The disease has been known by local communities since the end of the 19th century [25]. For about one century, Bandundu (and, to a lesser extent, the Muetshi District in the former Occidental Kasai province [26]) was acknowledged to be the sole focus of konzo in the DRC. However, in the late 1990s, new cases were reported in South-Kivu, a war-torn province located in the eastern DRC, more than $1000 \mathrm{~km}$ away from Bandundu [27]. As in former konzo outbreaks, the two major konzo risk factors (i.e., cassava-derived cyanide poisoning and malnutrition) were documented, and the new epidemics was restricted to Burhinyi (a rural district located about $65 \mathrm{~km}$ west of Bukavu, the capital city of the South-Kivu province) and its immediate neighborhood [27]. The reasons why the disease remained clustered to this area are still unclear, especially knowing that cassava is the staple food for most communities living in 
South-Kivu. Furthermore, cassava-derived dietary cyanide poisoning was already reported in Idjwi, another rural district of the province, in the 1970s, and was suspected to contribute to the high prevalence of endemic goiter in this region [21]. A recent survey confirmed the persistence of cassava-derived cyanide poisoning in Idjwi [28], while no case of konzo has been observed there so far. The same study pointed out that the most discriminating factor between Idjwi and Burhinyi was the nutritional level, which was by far worse in Burhinyi than in Idjwi, hence the hypothesis that nutritional status would be more determinant in the appearance of konzo in Burhinyi. In this perspective, dietary habits (changes) could also play a role. On the other hand, in Burhinyi, like in other konzo-affected areas, the peak incidence of konzo occurred during the dry season (DS) [27], and this seasonality is not yet fully explained. Whether it is solely related to seasonal variation (temperature, humidity, etc.) and its environmental consequences on cassava cultivars and population health or favored by season-related changes in dietary habits and/or in cassava processing is still an open question.

This study aimed to evaluate and compare the impact of seasonal variation regarding, on one side, the nutritional level, and on the other side, the efficiency of current cassava processing methods and on cyanide poisoning in Idjwi and Burhinyi, owing to their similar level of cassava-derived cyanide poisoning and differential appearance of konzo (see above), with the hypotheses that (1) the inefficiency of local processing methods in removing cyanogenic compounds from cassava roots is worse during the DS, more prominently in Burhinyi than in Idjwi, and (2) seasonal variation differently influences the nutritional level during the DS, with worsening of protein malnutrition in Burhinyi (but not in Idjwi) due to lower protein intake.

\section{Materials and Methods}

\subsection{Study Area}

This study was conducted in Burhinyi and Idjwi, two rural areas of South-Kivu province, in the eastern DRC. Detailed information on these areas is presented elsewhere [28]. In brief, Burhinyi is a mountainous area located in the territory of Mwenga, $\sim 65 \mathrm{~km}$ southwest of Bukavu (the capital city of the province), where konzo cases were first and solely reported in eastern DRC [27]. Idjwi is the largest island of the Kivu Lake located $\sim 50 \mathrm{~km}$ northeast of Bukavu (Figure 1). These two rural areas belong to the climate zone AW3 (wet tropical), according to the Köppen climate classification [29,30], with a short DS (June to August) and a long raining season (RS) (September to May). As elsewhere in the DRC, cassava products are predominant in the population's diet of both areas. As stated above, dietary cyanide poisoning from cassava prevails in both regions [28], associated to konzo in Burhinyi [27], contrary to Idjwi, where no konzo case has been so far reported, rather, a high prevalence of endemic goiter [21,31].

\subsection{Study Design and Ethical Considerations}

This repeated cross-sectional study was conducted in the frame of a larger project targeting risk factors and determinants of konzo in South-Kivu, during which data were collected between May and August 2018. In this report, we only present data on cassavarelated cyanide exposure and the nutritional status in patients suffering from konzo (in Burhinyi) or goiter (in Idjwi), as well as in age-matched healthy subjects from the same areas, in addition to the total cyanide content of fresh cassava roots and of cassava flour, collected directly from local fields and from households' stocks, respectively.

In order to confirm our working hypotheses, detailed information on cassava processing (e.g., used methods, and duration of each step) and dietary habits related to cassava were evaluated by individual interviews with participants, using a questionnaire. The efficiency of cassava processing methods was assessed by measuring the reduction in cyanide content between fresh roots and processed flour, and the proportion of flour samples containing residual cyanide contents above the safety threshold of 10 ppm [15]. Dietary cyanide poisoning was assessed using the uSCN level, which was 
considered to be high when exceeding $100 \mu \mathrm{mol} / \mathrm{L}$ (corresponding to the cutoff value of $6 \mathrm{mg} / \mathrm{g}$ creatinine for non-smokers individuals with normal kidney function [32]) or very high for values $\geq 344.0 \mu \mathrm{mol} / \mathrm{L}$ (these values were reported in several konzo-affected areas [23,33-35]). Serum proteins and albumin levels were used as biological markers of the nutritional status. Finally, in order to measure the impact of seasonal variation, we compared the values of these parameters in May (RS) and in August (DS) on both areas of interest.
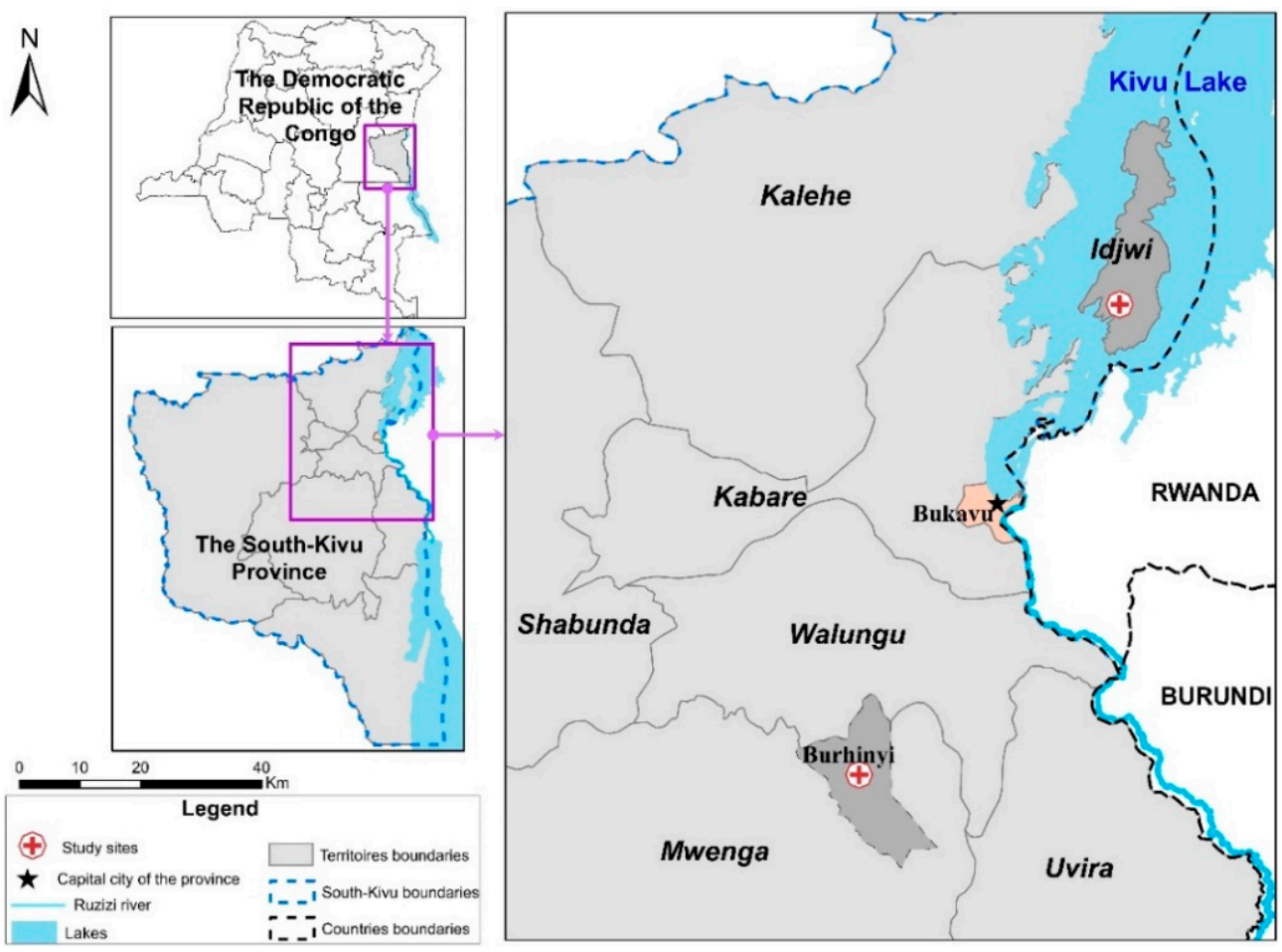

Figure 1. Map of the study area.

The study was approved by the ethical committee of the Universite Catholique de Bukavu (ethical approval code: UCB/CIE/NC/001/2017), by the Medical Ethics Committee (CME) of the Hasselt University (approval code: CME2017/764), and by the Social and Societal Ethics Committee (SMEC) of the Hasselt University (approval code: REC/SMEC/VRAI/178/104). All procedures were performed in accordance with the 1964 Declaration of Helsinki and its later amendments and following other national and international ethical standards. Prior to enrolment in the study, all adult participants gave their informed consent, while for those under the age of 18, the consent was obtained from parents (see below the detailed procedure).

\subsection{Participant Recruitment and Sampling}

This study included konzo patients living in Burhinyi and patients suffering from endemic goiter living in Idjwi (cases), these diseases having been factually and respectively demonstrated to be associated with cassava-derived cyanide exposure in these areas. In addition, age- and sex-matched healthy subjects from the same area (controls) were respectively included.

We closely collaborated with local community health workers (CHWs) for participants screening and recruitment. When CHWs went door to door for their regular activities in communities, they screened for potential participants fulfilling the inclusion criteria, respectively, in Idjwi (visible goiter) and in Burhinyi (the WHO criteria of konzo: $1^{\circ}$ a visible symmetric spastic abnormality of gait while walking or running; $2^{\circ}$ a history of onset of less than 1 week followed by a non-progressive course in a formerly healthy 
person; and $3^{\circ}$ bilaterally exaggerated knee or ankle jerks without signs of disease of the spine [24]). Exclusion criteria for controls consisted of medical history of motor impairment, irrespective of the etiology (in Burhinyi) and notion of goiter (in Idjwi), while in all participants (patients and controls from both areas), they consisted of (1) history of smoking (because smoking increases uSCN levels [36]; see below); (2) the existence of kidney failure (prolonging the urinary elimination half-life of thiocyanate (SCN) [36]); and (3) infection by the human immunodeficiency virus (HIV) (especially in Burhinyi, as the HIV-1 can cause spastic paraparesis [37]).

Recruitment consisted of a two-step procedure: first, eligible patients were orally given relevant information about the study in local dialects and were requested, if interested, to come to the local health center at a given date with a proxy of similar age ( \pm 5 years) and sex, not suffering from their disease, and in the case of those aged $<18$ years, also with their legal representative. On second contact, screened patients, as well as their healthy proxies and their legal respondent when applicable, were provided with detailed explanations about the study by the investigating team (medical doctors, agronomist, nurses, and trained medical students). Participants were finally included only after they (or their legal proxy if $<18$ years old) gave their informed consent and if investigators confirmed that they met inclusion criteria and had no exclusion criteria.

There was no sample calculation in this study, which conveniently included participants as much as possible, according to the contacts initiated through CHWs. A total of 94 subjects participated in the first survey (May), including 33 konzo patients and the same number of healthy controls from Burhinyi, as well as 14 patients with goiter and their respective controls from Idjwi. Among subjects included in the RS, 40 were lost to follow-up at the second survey (August) and were excluded from final comparative analyses, as they lacked data for the DS. Therefore, 54 (29 konzo patients and 11 healthy subjects from Burhinyi, 8 patients with goiter and 6 healthy subjects from Idjwi) with complete information collected for both seasons constituted the final population of this study (Figure 2). Initially, we were planning to conduct a 1:1 case-control design. However, owing to the lower number of controls with complete data for both seasons, case-control comparison tests were not performed in the final analyses.

In addition to clinical data, a total of 174 fresh cassava roots (108 in Burhinyi and 66 in Idjwi) and 111 cassava flour samples (59 in Burhinyi and 52 in Idjwi) were conveniently collected from local fields and households' stocks in Burhinyi and Idjwi as follows: in each selected village, a "starting point" was chosen as the nearest address to one patient (konzo patient in Burhinyi or goiter patient in Idjwi), from which we randomly chose a direction in which we went door to door, identifying all households growing cassava in their fields up to the village limits in that direction. In some villages (both in Burhinyi and Idjwi), however, there was no participant to the clinical study. Therefore, we obtained the consent of the chief in order to collect cassava roots or flour samples from all households, who had to give their consent as well in order to participate in cassava sample collection.

In each field, all varieties of cassava were identified. For each of them, one plant was harvested, and the largest cassava root taken from the plant. Additionally, a small amount (approximately $50 \mathrm{~g}$ ) of cassava flour was collected from the household stock. Collected cassava roots and flour samples were stored in dry and cool conditions $\left(\sim 8{ }^{\circ} \mathrm{C}\right)$ for a maximum of $24 \mathrm{~h}$ before their cyanide content was measured.

\subsection{Data Collection}

Each recruited participant was given an individual unique code based on the rank on the enrolment list, the month and year of birth, sex, and medical status (patient or control). This code was used throughout data collection and analysis to identify the participant, for confidentiality and according to ethical recommendations.

All subjects were interviewed on their medical history regarding spastic paraparesis (Burhinyi) or goiter (Idjwi), and their dietary habits (including cassava growing, processing methods, and consumption). Food intake was qualitatively assessed using a $72 \mathrm{~h}$ dietary 
recall. In addition, participants were asked about the consumption of other cyanogenic foods, such as bitter almonds or bamboo sprouts.

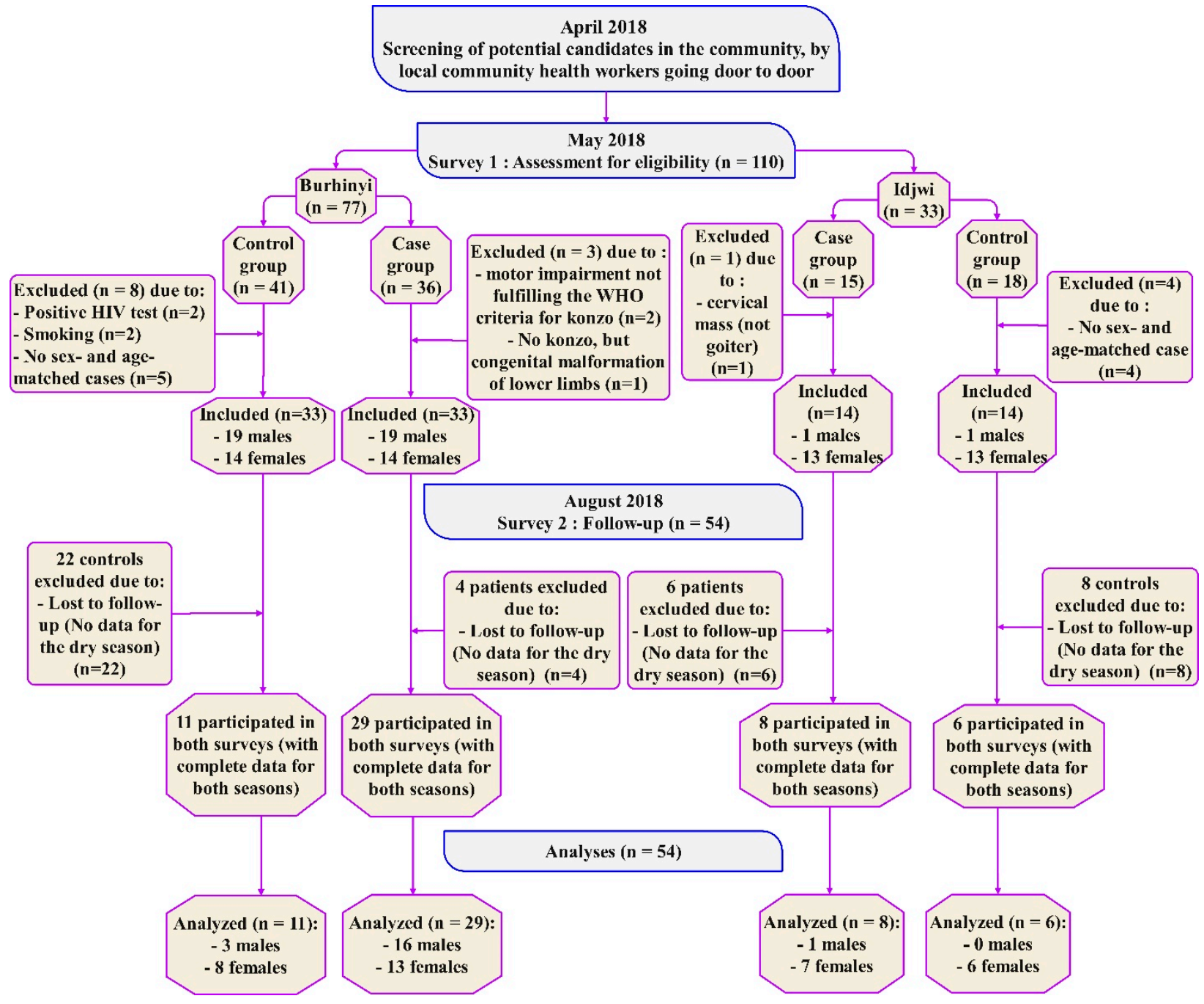

Figure 2. Flowchart of the study participants recruitment.

In addition to a general physical and neurological examination, they gave each one urine sample collected in a sterile $50 \mathrm{~mL}$ tube the day of their clinical examination. Fresh collected urine samples were immediately labeled with the participant's code, put on ice in closed boxes for one to six hours, then deep frozen at $-40{ }^{\circ} \mathrm{C}$ until they were processed for uSCN measurements. In addition, a total of 444 blood samples (three samples per participant) were collected in red-top $5 \mathrm{~mL}$ tubes with no additive, immediately labeled thereafter with the patient's individual codes, and centrifuged within $30 \mathrm{~min}$ to one hour using the Omega 6 centrifuge machine at 3600 revolutions per minute (corresponding to $1600 \times g$ ) for $10 \mathrm{~min}$. The obtained aliquots were put in separate cryotubes, then deep frozen at $-40{ }^{\circ} \mathrm{C}$ until they were processed for serum creatinine, albumin and total proteins measurements, and HIV serological tests. Finally, fresh cassava roots and processed flour samples were collected for total cyanide content measurement (for more details, see Section 2.3. above).

\subsection{Data Processing and Analysis}

\subsubsection{Data Processing}

The cyanide content of fresh roots and of cassava flour was measured by using semiquantitative colorimetric methods with the "kit A", according to Dr. Bradbury's protocol 
(School of Botany and Zoology, Australian National University) [38]. uSCN levels were measured by using the "kit D1", following Dr. Bradbury's protocol (School of Botany and Zoology, Australian National University) [39]. Serum creatinine was measured in all participants, and the Modification of Diet in Renal Disease (MDRD) equation was computed to evaluate the estimating glomerular filtration rate (GFR). All participants had a GFR above $60 \mathrm{~mL} / \mathrm{min} / 1.73 \mathrm{~m}^{2}$, witnessing normal kidney function. Therefore, the abovementioned normal reference value $(<100 \mu \mathrm{mol} / \mathrm{L})$ was used for measured $\mathrm{uSCN}$ in all participants.

\subsubsection{Statistical Analyses}

The Pearson's chi-squared test (or Fisher's exact test when at least one expected cell size was $<5$ ) was used to compare categorical data. The paired $t$-test or the Wilcoxon signed-rank test was used to compare matched quantitative data between the RS and the DS, based on whether the data were normally distributed or not, while the unpaired $t$-test or Mann-Whitney test was used to compare unmatched quantitative data. To evaluate the association between very high uSCN levels and different factors, a simple logistic regression was used by computing the crude odds ratio (OR) along with $95 \%$ confidence interval $(95 \% \mathrm{CI})$, and then a multivariable logistic regression model was built to identify factors independently associated with very high uSCN by computing adjusted OR (and corresponding 95\% CI). This model included all variables with a p-value below 0.25 in the simple logistic regression. Finally, we assessed the association between (1) uSCN and total cyanide content in the cassava flour sample (in the RS), and (2) uSCN and serum protein levels by computing the Spearman's rank correlation.

Statistical significance was defined by $p<0.05$, and analyses were performed by using the Epi Info software, Version 7.2.4.0 (CDC, Atlanta, GA, U.S.A., 2020) and GraphPad Prism version 9.0.0 for Windows (GraphPad Software, San Diego, CA, U.S.A.). A two-tailed $p<0.05$ was considered to indicate a statistically significant difference.

\section{Results}

\subsection{General Characteristics of the Surveyed Population}

In this study, a total of 94 subjects (66 from Burhinyi and 28 from Idjwi), aged $28.8 \pm 12.0$ years old, $59.6 \%$ female, were screened. Out of them, 54 subjects, respectively, from Burhinyi (40) and from Idjwi (14) with complete datasets were included in the final comparative analyses, whose sociodemographic characteristics are shown in Table 1. The final study population did not drastically differ from the screened groups (see Table S1 provided as supplementary material).

\subsection{Cassava Consumption Habits, Farming Practices and Processing Methods}

Cassava was more predominantly consumed during the DS, especially in Burhinyi. In fact, the proportion of participants reporting having eaten cassava $\geq 2 / 3$ last days similarly increased during the DS in Burhinyi (from 80\% to 95\%) and in Idjwi (from $78.6 \%$ to $92.9 \%$ ) compared to the RS, but the seasonal difference reached significance only in Burhinyi ( $p=0.0425$ and $p=0.5956)$. Despite the prominent presence of a cassava culture, dietary cassava products did not always come from the field owner's production, as some participants reported to consuming cassava bought from local markets (Burhinyi: 30\% in RS and $17.5 \%$ in DS, $p=0.1990$; Idjwi: $28.6 \%$ in RS and DS, $p=1.0000$ ). Some participants reported exclusively eating bitter cassava foods, especially in Idjwi in DS (Burhinyi vs. Idjwi: $30.0 \%$ vs. $50 \%, p=0.2064$ in RS; $30.0 \%$ vs. $64.3 \%, p=0.0235$ in DS), while others ate more sweet cassava roots or a mixture of both.

Cassava was harvested approximately 12 months after planting (11.8 \pm 1.7 and $11.6 \pm 1.3$ months in Burhinyi and Idjwi, respectively, $p=6223)$. Both communities grew bitter and sweet varieties of cassava. Table 2 shows that cassava cultivars grown in both areas had high cyanide content in fresh roots. Of notice, sweet varieties (considered to contain 
low cyanide levels) displayed cyanide concentrations above 50 ppm (median 30-100 ppm) although still lower than bitter varieties (median $>100$ ppm).

Table 1. Sociodemographic characteristics of the final study population.

\begin{tabular}{|c|c|c|c|c|}
\hline Characteristics & $\begin{array}{l}\text { General Group } \\
\quad(\mathrm{n}=54)\end{array}$ & $\begin{array}{l}\text { Burhinyi } \\
(n=40)\end{array}$ & $\begin{array}{c}\text { Idjwi } \\
(n=14)\end{array}$ & $p$ \\
\hline Age (years) * & $28.7(12.1)$ & $25.8(11.8)$ & $36.9(9.0)$ & $0.0023^{1}$ \\
\hline \multicolumn{5}{|c|}{ Sex } \\
\hline Female & $34(63.0)$ & $21(52.5)$ & $13(92.9)$ & $0.0071^{2}$ \\
\hline Male & $20(37.0)$ & $19(47.5)$ & $1(7.1)$ & \\
\hline \multicolumn{5}{|c|}{ Level of completed education } \\
\hline None & $37(68.5)$ & $29(72.5)$ & $8(57.1)$ & $0.5446^{3}$ \\
\hline Primary school & $12(22.2)$ & $8(20.0)$ & $4(28.6)$ & \\
\hline Secondary school & $5(9.3)$ & $3(7.5)$ & $2(14.3)$ & \\
\hline \multicolumn{5}{|c|}{ Occupation } \\
\hline Farmer & $37(68.5)$ & $26(65.0)$ & $11(78.6)$ & $0.5073^{3}$ \\
\hline Other & $17(31.5)$ & $14(35.0)$ & $3(21.4)$ & \\
\hline \multicolumn{5}{|c|}{ Growing cassava } \\
\hline Yes & $54(100.0)$ & $40(100.0)$ & $14(100.0)$ & $1.0000^{2}$ \\
\hline No & $0(0.0)$ & $0(0.0)$ & $0(0.0)$ & \\
\hline \multicolumn{5}{|c|}{ Main source of income } \\
\hline Harvests & $52(96.3)$ & $38(95.0)$ & $14(100.0)$ & $1.0000^{3}$ \\
\hline Other & $2(3.7)$ & $2(5.0)$ & $0(0.0)$ & \\
\hline
\end{tabular}

* Data for age are means (standard deviation), all other are n (\%). ${ }^{1}$ Unpaired $t$-test; ${ }^{2}$ Pearson's chi-squared test

${ }^{3}$ Fisher's exact test.

Table 2. Varieties and cyanide content in (fresh) cassava roots grown in Burhinyi and Idjwi.

\begin{tabular}{|c|c|c|c|}
\hline Cassava Varieties & $\mathrm{Nb}$ of Samples & Taste & $\begin{array}{c}\text { Cyanide Content } \\
(\mathrm{ppm})^{1}\end{array}$ \\
\hline \multicolumn{4}{|c|}{ In Burhinyi } \\
\hline Nyangezi & 34 & Bitter & $200(100-400)$ \\
\hline M'Kabuye & 16 & Bitter & $150(100-400)$ \\
\hline Chidukura & 38 & Sweet & $50(50-100)$ \\
\hline Majambere & 4 & Sweet & $75(50-450)$ \\
\hline Other bitter varieties & 13 & Bitter & $100(50-100)$ \\
\hline Other sweet varieties & 7 & Sweet & $50(30-100)$ \\
\hline \multicolumn{4}{|c|}{ In Idjwi } \\
\hline Kalimira & 36 & Bitter & $200(150-400)$ \\
\hline Nyamalirwa & 12 & Bitter & $150(100-400)$ \\
\hline Mulibwa & 10 & Sweet & $75(30-100)$ \\
\hline Other sweet varieties & 8 & Sweet & $50(30-100)$ \\
\hline
\end{tabular}

${ }^{1}$ Data are median (interquartile range); $\mathrm{Nb}$ : number; ppm: parts per million.

Upon harvest, cassava roots were successively peeled, sun dried, and heap fermented before being milled to produce the flour in both areas. Water soaking was not practiced in these communities. Cassava roots were also consumed fresh, albeit more systematically in Idjwi (all participants) than in Burhinyi $(67.5 \%, p=0.0013)$. Cassava flour is used to make "ugali" (a kind of hard porridge obtained by kneading cassava flour in boiling water), the main staple food for all participants. The traditional standard processing duration was described as the following (respectively in Burhinyi and Idjwi): sun drying ( $\sim 3$ and $\sim 7$ days), and heap fermentation ( $\sim 2$ and $\sim 1$ days). The current processing steps and their respective durations in Idjwi and Burhinyi are summarized in Table 3. It is clear from these data that the processing duration has shortened during the last decade $(53.6 \%$ of participants in Burhinyi and 41.2\% in Idjwi, $p=0.4901$ ). 
Table 3. Duration of cassava processing methods by seasons and areas.

\begin{tabular}{|c|c|c|c|c|}
\hline \multirow{2}{*}{ Area } & \multirow{2}{*}{$\mathbf{N}$} & \multicolumn{2}{|c|}{ Duration (in Days) of the Processing ${ }^{1}$} & \multirow[t]{2}{*}{$p^{2}$} \\
\hline & & Rainy Season & Dry Season & \\
\hline \multicolumn{5}{|c|}{ Total processing length } \\
\hline Burhinyi & 40 & $4.5(3.0-6.0)$ & $3.5(3-5)$ & 0.0290 \\
\hline Idjwi & 14 & $7.5(7.0-11.0)$ & $7.0(6-8)$ & 0.0508 \\
\hline$p^{3}$ & - & $<0.0001$ & $<0.0001$ & - \\
\hline \multicolumn{5}{|c|}{ Sun-drying length } \\
\hline Burhinyi & 40 & $3.0(2.0-4.0)$ & $2.0(2.0-3.5)$ & 0.0167 \\
\hline Idjwi & 14 & $7.0(7.0-9.0)$ & $6.0(5.0-6.0)$ & 0.0039 \\
\hline$p^{3}$ & - & $<0.0001$ & $<0.0001$ & - \\
\hline \multicolumn{5}{|c|}{ Heap fermentation length } \\
\hline Burhinyi & 40 & $2.0(1.0-3.0)$ & $2.0(1.0-2.0)$ & 0.1752 \\
\hline Idjwi & 14 & $1.0(0.0-3.0)$ & $2.0(0.0-3.0)$ & 0.1875 \\
\hline$p^{3}$ & - & 0.0828 & 0.3896 & - \\
\hline
\end{tabular}

Despite similar overall processing methods in Burhinyi and Idjwi, slight differences appeared. The total processing duration was $\sim 40 \%$ and $50 \%$ shorter in Burhinyi, respectively, in RS and DS (see Table 3), most probably due to shorter sun drying ( $60 \%$ and $\sim 65 \%$ lower duration in RS and DS, respectively). However, a larger proportion of participants practiced heap fermentation in Burhinyi than in Idjwi, especially during the RS $(100 \%$ vs. $50 \%$ in the RS, $p<0.0001$ ), whereas the difference became non-significant during the DS $(90.0 \%$ vs. $71.4 \%, p=0.1832)$. Furthermore, while bitter and sweet varieties of cassava were both indifferently processed in Burhinyi to produce flour, only bitter roots were processed in Idjwi (sweet roots were just boiled or even eaten raw). In summary, while the processing duration was equally shortened in both areas (especially sun drying), heap fermentation tended to be less frequently performed during DS in Burhinyi (although indifferently applied to sweet and bitter cassava varieties) than in Idjwi (where it was selectively applied to bitter cassava).

The total cyanide content in fresh cassava roots and in the processed flour is presented in Table 4. The processing methods used in both areas resulted in a drastic drop ( $95 \%)$ in the total cyanide content, especially during the RS when it reached safety levels $(0)(0-10)$ ppm in Burhinyi [23.1\% > $10 \mathrm{ppm}]$ and $10(5-10) \mathrm{ppm}$ in Idjwi [17.7\% > $10 \mathrm{ppm}], p=0.2172$ [and $p=0.6687])$. On the contrary, the DS witnessed significantly higher residual cyanide concentrations in flour samples both in Burhinyi $(p=0.0212)$ and in Idjwi $(p=0.0080)$ (Figure $3 \mathrm{a}, \mathrm{b}$ ), with $42.4 \%$ and $48.6 \%$ of samples above $10 \mathrm{ppm}$, respectively, in Burhinyi $(p=0.1224)$ and Idjwi $(p=0.0332)$. No statistical difference in cyanide content was observed between the two areas overall.

Table 4. Content in cyanide of raw cassava roots and cassava flour by seasons and areas.

\begin{tabular}{|c|c|c|c|c|c|}
\hline & \multicolumn{3}{|c|}{ Rainy Season } & \multirow{2}{*}{$\begin{array}{c}\text { Dry Season } \\
\text { Cyanide } \\
\text { Content }^{1}\end{array}$} & \multirow[b]{2}{*}{$p$} \\
\hline & $\mathbf{n}$ & $\begin{array}{l}\text { Cyanide } \\
\text { Content }\end{array}$ & $\mathbf{n}$ & & \\
\hline \multicolumn{6}{|c|}{ Fresh cassava roots } \\
\hline In Burhinyi & 46 & $100(50-200)$ & 62 & $100(50-200)$ & 0.7279 \\
\hline In Idjwi & 26 & $150(100-200)$ & 40 & $200(75-300)$ & 0.7819 \\
\hline$p$ & - & 0.2922 & - & 0.0735 & - \\
\hline \multicolumn{6}{|c|}{ Cassava flour } \\
\hline In Burhinyi & 26 & $0(0-10)$ & 33 & $10(5-20)$ & 0.0212 \\
\hline In Idjwi & 17 & $10(5-10)$ & 35 & $10(10-30)$ & 0.0080 \\
\hline$p$ & - & 0.2172 & - & 0.1235 & - \\
\hline
\end{tabular}

${ }^{1}$ Data are median (interquartile range), unit $=$ ppm. All $p$ values are by Mann-Whitney test. 


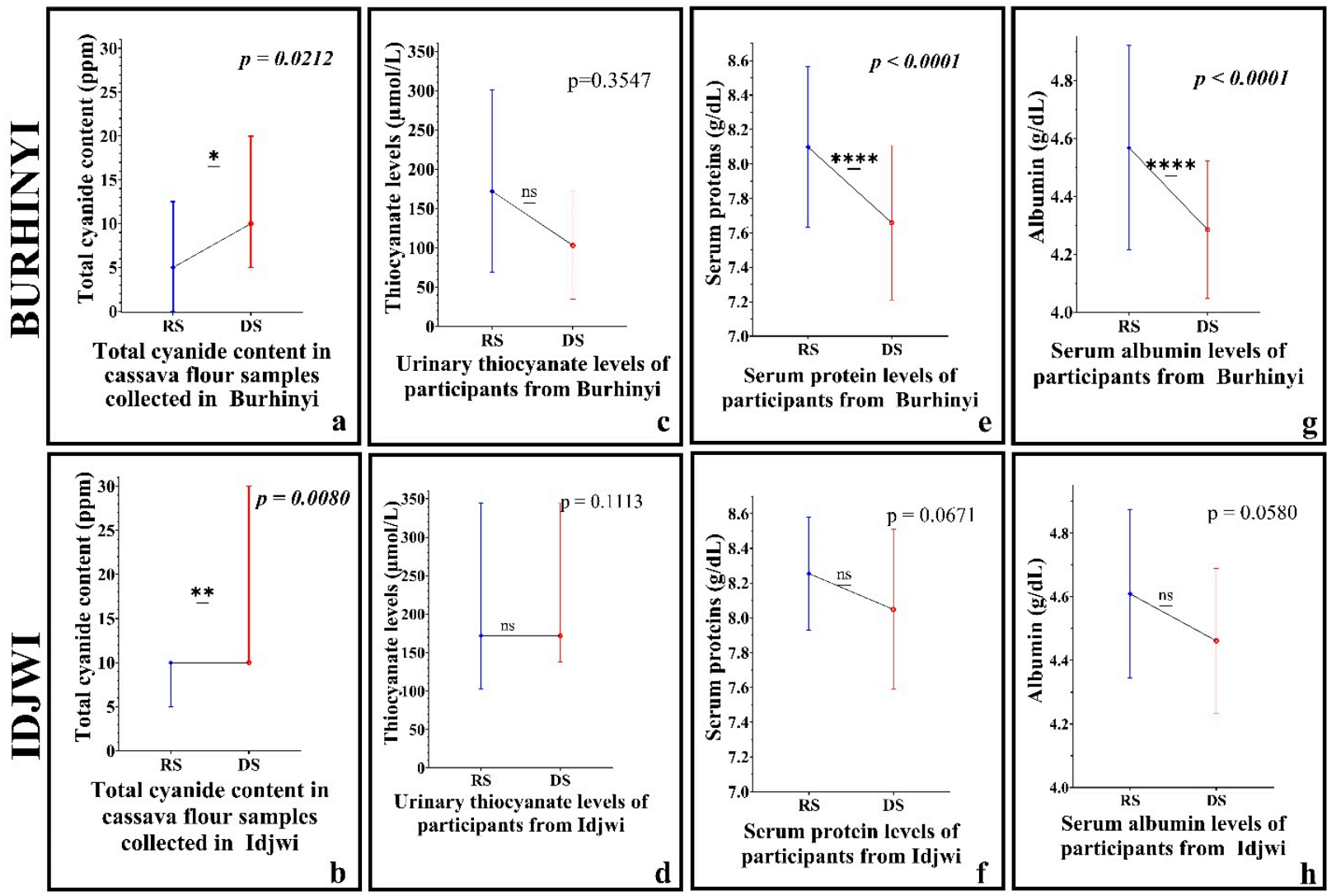

Figure 3. Seasonal variations of dietary cyanide exposure and nutritional status (serum proteins and albumin levels). This figure shows the impact of seasonal variation on $1^{\circ}$ the total cyanide content in cassava flour samples: significant increase during the dry season in Burhinyi (a) and Idjwi (b), $2^{\circ}$ the urinary thiocyanate levels: non-significant decrease in Burhinyi (c) and slight (non-significative) increase in Idjwi (d) during the dry season, and $3^{\circ}$ the serum proteins and albumin levels: significant decrease during the dry season in Burhinyi $(\mathbf{e}, \mathbf{g})$ but not in Idjwi $(\mathbf{f}, \mathbf{h})$. Data are presented as a median with an interquartile range (a-d) or as mean with standard deviation (e-h). RS, rainy season; DS, dry season; ppm, parts per million; ns, not significant; ${ }^{*} p<0.05$; ${ }^{* *} p<0.01$; ${ }^{* * *} p<0.0001$.

\subsection{Protein Dietary Intake and Nutritional Status}

Cassava foods were mostly eaten with vegetables as a side dish, while animal protein intake was limited (especially in Burhinyi), although widely varied during the RS and the DS, as explained below. Over the last three days before evaluation, the following proportion of people from Burhinyi reported eating at least once the mentioned foods: meat $37.5 \%$ in the RS and $45.0 \%$ in the DS, $p=0.4957)$, fish $(10.0 \%$ and $17.5 \%, p=0.3301)$, milk $(15.0 \%$ and $12.5 \%, p=0.7454)$, or eggs $(5.0 \%$ and $0.0 \%, p=0.4936)$. Participants from Idjwi had significantly more access to fish ( $57.1 \%$ in the RS, $p=0.0009$ and $71.4 \%$ in the DS, $p=0.0004$ ), but were equally deprived from access to the other protein sources (all $p>0.05$ ).

Participants from Burhinyi and Idjwi had similar serum proteins levels $(8.1 \pm 0.5 \mathrm{~g} / \mathrm{dl}$ vs. $8.3 \pm 0.3 \mathrm{~g} / \mathrm{dl}, p=0.3694)$ and albumin levels $(4.6 \pm 0.4 \mathrm{~g} / \mathrm{dl}$ vs. $4.6 \pm 0.3 \mathrm{~g} / \mathrm{dl}$, $p=0.6351$ ) during the RS, while both became significantly lower in Burhinyi during the DS $(p=0.0023$ and $p=0.0097$, respectively for protein and albumin levels) (see also Figure $3 \mathrm{e}-\mathrm{h}$ ).

\subsection{Urinary SCN Concentrations and Determinants}

The prevalence of participants with high uSCN concentrations was similarly high in Burhinyi and in Idjwi (respectively, $65.0 \%$ and $85.7 \%$ in the RS, $p=0.1872 ; 57.5 \%$ and $78.6 \%$ in the DS, $p=0.1600$ ), without any difference noticed between seasons. The median uSCN values led to the same observations during the RS (i.e., similarly high levels: 
172.0 (68.8-258.0) $\mu \mathrm{mol} / \mathrm{L}$ in Burhinyi and 172.0 (103.2-344.0) $\mu \mathrm{mol} / \mathrm{L}$ in Idjwi, $p=0.3969)$, but during the DS, uSCN concentrations were significantly lower in Burhinyi than in Idjwi (103.2 (34.4-172.0) $\mu \mathrm{mol} / \mathrm{L}$ vs. 172.0 (172.0-344.0) $\mu \mathrm{mol} / \mathrm{L}, p=0.0414)$. Again, no difference was noticed between seasons within one area $(p=0.3547$ in Burhinyi and 0.1113 in Idjwi) (Figure 3c,d). Overall, it appears that the contrast between the two areas was more remarkable during the DS than during the RS, although no significant seasonal reduction could be detected within each area.

During the DS, significantly higher uSCN levels were noticed in participants who reported exclusively eating foods from bitter cassava roots $(172.0(103.2-344.0) \mu \mathrm{mol} / \mathrm{L})$ as compared with those who ate mostly sweet cultivars or a mixture of both sweet and bitter varieties (103.2 (34.4-172.0) $\mu \mathrm{mol} / \mathrm{L}, p=0.0214)$. Likewise, participants who skipped heap fermentation during cassava processing had higher uSCN levels (344.0 (258.0-688.0) $\mu \mathrm{mol} / \mathrm{L})$ compared to those who fermented cassava for at least one day $(103.2(34.4-172.0) \mu \mathrm{mol} / \mathrm{L}$, $p=0.0051)$. On the other hand, neither the reported total duration of cassava processing, nor the duration of sun drying significantly influenced uSCN levels $(p>0.05)$. Overall, $24.1 \%$ of the study population $(10 / 54)$ had very high uSCN concentrations (i.e., uSCN $\geq 344.0$ $\mu \mathrm{mol} / \mathrm{L})$, which was independently associated in DS with a predominant consumption of bitter cassava foods $(\mathrm{OR}=5.43, p=0.0144)$ and to skipping heap fermentation during cassava processing $(\mathrm{OR}=16.67, p=0.0021)$ (Table 5).

Thus, increasing the consumption of bitter and bypassing heap fermentation (but not shorter processing and sun drying) determined higher uSCN urinary concentrations during the DS.

Of notice, a significant positive correlation was found between uSCN levels and serum proteins in Burhinyi during the RS ( $\rho=0.49,95 \%$ CI: 0.19 to $0.71, p=0.0018$ ), but not during the DS ( $\rho=-0.07,95 \%$ CI: -0.40 to $0.27, p=0.6636$ ) (Figure 4 ). No significant correlation was found between uSCN and serum proteins levels in Idjwi in either season (RS: $\rho=-0.32$, $95 \%$ CI: -0.74 to $0.26, p=0.2530$, DS: $\rho=0.10,95 \%$ CI: -0.47 to $0.61, p=0.7329)$.

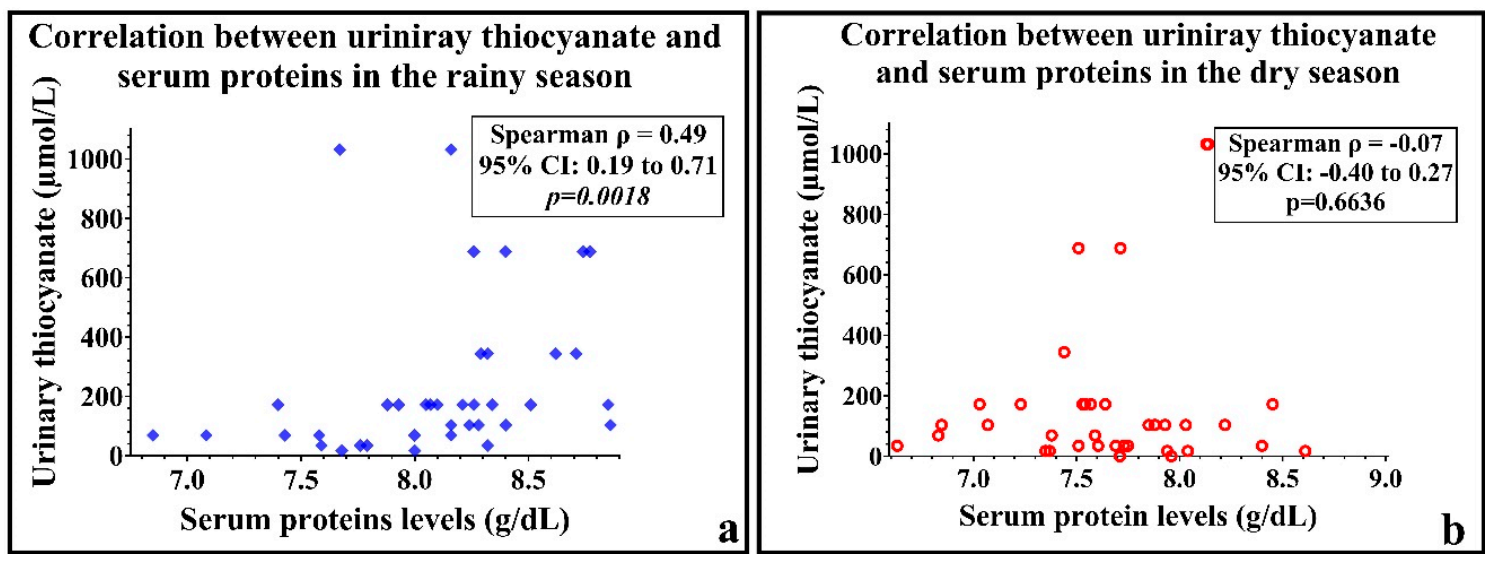

Figure 4. Correlation between urinary thiocyanate and serum protein levels during the rainy season (a) and the dry season (b) in Burhinyi, using the Spearman's rank correlation coefficient. This figure shows a significant correlation between these two factors during the rainy season but not during the dry season.

Finally, from the 54 included participants, 16 provided cassava flour samples. A weak but non-significant positive correlation was found between uSCN levels of the 16 participants and the cyanide content in corresponding cassava flour $(\rho=0.30,95 \%$ CI: -0.23 to $0.69, p=0.2600)$. 
Table 5. Factors associated with very high urinary thiocyanate levels during the dry season.

\begin{tabular}{|c|c|c|c|c|c|c|c|}
\hline \multirow{2}{*}{ Variables } & \multirow{2}{*}{$\begin{array}{c}\text { Very High uSCN }{ }^{1} \\
\text { n (\%) }\end{array}$} & \multicolumn{3}{|c|}{ Crude OR } & \multicolumn{3}{|c|}{ Adjusted OR } \\
\hline & & OR & $95 \%$ CI & $p$ & OR & $95 \% \mathrm{CI}$ & $p$ \\
\hline \multicolumn{8}{|c|}{ Sex } \\
\hline Female & $10(29.4)$ & 2.35 & $0.56-9.85$ & 0.2408 & 5.63 & $0.57-55.96$ & 0.1405 \\
\hline Male & $3(15.0)$ & 1 & - & & 1 & & \\
\hline \multicolumn{8}{|c|}{ Location } \\
\hline Burhinyi & $7(17.5)$ & 0.28 & $0.07-1.08$ & 0.0638 & 3.81 & $0.18-79.75$ & 0.3890 \\
\hline Idjwi & $6(42.9)$ & 1 & - & & 1 & & \\
\hline \multicolumn{8}{|c|}{ Medical status } \\
\hline Goiter patients & $4(50.0)$ & 4.80 & $0.89-25.96$ & 0.0685 & - & - & - \\
\hline Controls from Idjwi & $2(33.3)$ & 2.40 & $0.34-16.90$ & 0.3793 & - & - & - \\
\hline $\begin{array}{l}\text { Controls from } \\
\text { Burhinyi }\end{array}$ & $2(18.2)$ & 1.07 & $0.17-6.52$ & 0.9443 & - & - & - \\
\hline Konzo patients & $5(17.2)$ & 1 & - & & & & \\
\hline \multicolumn{8}{|c|}{ Most consumed cassava varieties } \\
\hline Exclusively bitter & $9(42.9)$ & 5.43 & $1.40-21.11$ & 0.0144 & 10.27 & $1.37-76.91$ & 0.0233 \\
\hline Either sweet or both & $4(12.2)$ & 1 & - & & 1 & & \\
\hline \multicolumn{8}{|c|}{ Main source of cassava } \\
\hline Market & $3(27.3)$ & 1.24 & $0.28-5.57$ & 0.7812 & - & - & - \\
\hline Familial farm & $10(23.3)$ & 1 & - & & & & \\
\hline \multicolumn{8}{|c|}{ Eating raw cassava roots } \\
\hline Yes & $11(26.8)$ & 2.01 & $0.38-10.55$ & 0.4080 & - & - & - \\
\hline No & $2(15.4)$ & 1 & - & & & & \\
\hline \multicolumn{8}{|c|}{ Total duration of processing } \\
\hline $1-3$ days & $4(20.0)$ & 0.69 & $0.18-2.64$ & 0.5923 & - & - & - \\
\hline$\geq 4$ days & $9(26.5)$ & 1 & - & & & & \\
\hline \multicolumn{8}{|c|}{ Duration of sun-drying } \\
\hline $1-3$ days & $5(16.7)$ & 0.40 & $0.11-1.44$ & 0.1613 & 0.27 & $0.02-3.70$ & 0.3245 \\
\hline$\geq 4$ days & $8(33.3)$ & 1 & - & & 1 & & \\
\hline \multicolumn{8}{|c|}{ Practicing heap fermentation } \\
\hline No (0 day) & $6(75.0)$ & 16.67 & 2.78-99.90 & 0.0021 & 35.89 & $3.03-425.59$ & 0.0045 \\
\hline Yes ( $\geq 1$ day) & $7(15.2)$ & 1 & & & 1 & & \\
\hline
\end{tabular}

${ }^{1}$ Prevalence of participants with urinary thiocyanate levels $\geq 344.0 \mu \mathrm{mol} / \mathrm{L}$; OR, odds ratio; 95\% CI, 95\% confidence interval.

\section{Discussion}

The aim of this study was to evaluate the impact of seasons on the nutritional status and on dietary cassava-related cyanide exposure, in two areas of the DRC South-Kivu province (Burhinyi and Idjwi) differently affected by konzo and malnutrition, although similarly witnessing cassava-derived cyanide toxicity. We made the hypothesis that the DS would negatively influence those parameters, especially in Burhinyi, as part of the explanation regarding the differential appearance of konzo in these two areas. In order to demonstrate our assumptions, we collected, through this repeated cross-sectional study conducted respectively in the RS and in the DS, detailed information on the dietary habits and farming practices focused on cassava and measured dietary cyanide content in cassava products. Additionally, the uSCN and biological markers of the nutritional status were assessed at these two time points in patients who underwent diseases supposedly related to cassava toxicity (i.e., konzo in Burhinyi and endemic goiter in Idjwi) and healthy controls. The final population with the complete dataset consisted of 37 cases and 17 controls.

\subsection{Local Processing Methods Are Efficient in RS but Not in DS}

Information collected during individual interviews did not show other evident dietary sources of cyanide exposure than cassava in both areas. Cassava cultivars grown in these 
areas had equally high cyanide content during the RS as well as during the DS, regardless of their taste, even if sweet varieties tended to contain less cyanide. In contrast, cyanide concentrations observed in flour obtained from processed cassava was in the great majority of samples, below the safety level overall. Nevertheless, when looking further into seasonal variations, it was clear that during the DS, approximately half of the flour samples contained toxic levels of cyanide in both areas. This seasonal discrepancy could arise either from higher fresh root cyanide content during DS (already reported elsewhere [8], mainly due to water stress on the plant because of the drought [9]), or from less efficient processing.

Our data did not show seasonal differences in fresh root cyanide concentrations in both areas, but most participants reported a shortcut in cassava processing during the DS, which was confirmed by shorter overall processing duration, especially the sun-drying step. This could eventually account for the above-mentioned discrepancy, owing to higher residual cyanohydrin levels in cassava products $[17,18,40]$. However, it was shown that once the relative moisture reaches low values in cassava roots, modifying the duration of the sun-drying step has no further influence on the decrease in the dried roots' cyanide content, due to the interruption in enzymatic degradation [40]. In fact, in South-Kivu, during the DS, temperatures are warmer, with longer sunshine exposure per day and lower ambient relative moisture [41]. These conditions may lead to a quicker drying of cassava roots, which results in low root moisture $(<15 \%)$, prematurely interrupting the removal of cyanogenic compounds, before the residual cyanide reaches safe levels [42,43]. Such geo-environmental factors may have largely contributed to the inefficiency of traditional processing methods during the DS in Burhinyi and Idjwi. Supporting this assumption, it was shown that repeatedly wetting and sun-drying cassava flour increases the rate of cyanide removal up to the safety level $[23,44]$, most probably thanks to renewed moisture, allowing further enzymatic degradation. The wetting method has shown to be easy to implement, even in poor populations $[23,45]$, probably because it does not require to prolong the processing procedure and remains compatible with the maintenance of household stocks of cassava flour in conditions of food deprivation.

\subsection{Consumption of Bitter Cassava and Skipping Heap Fermentation Are Associated with Very High uSCN Levels}

Participants from both areas who reported skipping heap fermentation during cassava processing and restricted their cassava processing to sun-drying had significantly higher uSCN levels, witnessing higher dietary cyanide poisoning, compared to those who fermented cassava roots at least for one day prior to its consumption. Several studies have shown the high efficiency of heap fermentation, which removes up to $98-99 \%$ of cyanogenic compounds [7,43,46,47], in contrast with sun-drying alone [43,48,49]. Accordingly, our data showed that more exclusive consumption of bitter cassava and skipping of heap fermentation (and performing sun drying alone) independently increased the odds of having very high uSCN levels, while no association was found between the total processing (or sun drying) duration and the uSCN levels. However, our data did not show differences between Burhinyi and Idjwi regarding processing shortcuts, in contradiction with Banea JP et al., who found an association between konzo outbreak in Bandundu (western DRC) and frequent shortcuts in cassava processing, especially a shorter fermentation [18]. Thus, Burhinyi and Idjwi appeared, once more, to undergo similar cassava-derived cyanide exposure, regardless of their differences in the occurrence of konzo, as previously observed [28].

\subsection{Seasonal Variation Does Not Induce uSCN Modification}

This study showed high uSCN levels in participants from Idjwi and Burhinyi, witnessing persistent dietary cyanide poisoning in both areas $[27,28]$. As stated above, growing bitter cassava (and to a lesser extent, also sweet toxic varieties), as well as shortening or skipping heap fermentation during the processing, prominently contributed to cyanide exposure, although our results could not show a significant correlation between the cyanide 
content of cassava flour and uSCN (the study was not specifically designed for this type of analysis).

Strikingly, uSCN levels were found to be similarly high in both seasons, while the cyanide content of cassava flour was subject to seasonal variation in both areas (remaining within safe ranges during the RS). One explanation for high uSCN during the RS could be that fresh cassava roots (whose cyanide content was not modified though seasons) remarkably contributed to cassava-related cyanide exposure, with a prominent effect on uSCN, which was already shown in Burhinyi [27]. Although cassava fresh roots are consumed in both regions (more systematically in Idjwi than in Burhinyi), we have no indication that they predominate among cassava products in the diet. Thus, alternative explanation should be searched for steadily high uSCN concentrations.

When comparing uSCN in the RS and in the DS, the contrast between Burhinyi and Idjwi was only significant in the DS, with lower uSCN in Burhinyi, in accordance with a higher proportion of cassava flour samples containing toxic cyanide levels in Idjwi. However, this observation is difficult to understand in light of the presence of Konzo in Burhinyi and of the deleterious effect of the DS in outbreak occurrence [18,27,50,51], from which one would expect higher uSCN in Burhinyi than in Idjwi, particularly during the DS. The existence of other sources of cyanide exposure in Idjwi could be questioned as a possible explanation for higher uSCN in Idjwi. However, no other cyanogenic food was identified in the diet of Idjwi participants, and industrial sources of exposure are unlikely in this poor region where no factory exists. Additionally, cyanide is not used in subsistence agriculture and petty trading (the main local economic activities).

Possible underestimation of cyanide exposure measured by uSCN in malnourished individuals (due to lower SCN synthesis capacity) from Burhinyi was already evoked in our previous data [28]. In this study, the serum protein level was lower in participants from Burhinyi in the DS compared to the RS, contrary to those from Idjwi who did not witness seasonal modification. On one hand, this finding confirms a rapid deterioration of the nutritional status (especially lower serum albumin level) between the RS and the DS in Burhinyi, as previously postulated in the new paradigm favoring a prominent role of acute nutritional worsening in the appearance of konzo [28]. As a consequence, the abovementioned underestimation of cyanide poisoning though uSCN measurement would be more prominent in the DS in Burhinyi.

Overall, it appears that the lack of uSCN seasonal variation does not reflect a steadily high cyanide exposure, especially in Burhinyi, further suggesting a possible underestimation due to lowered SCN synthesis capacity (resulting in lower uSCN) in people undergoing acute worsening of their (already impaired) nutritional status. Disruption in the correlation between serum protein and USCN in the DS in Burhinyi could be understood in the frame of the rapid nutritional deterioration. In light of these observations, it is plausible that participants from Burhinyi underwent higher cyanide exposure during the DS, especially if we consider the higher cyanide content in cassava flour observed during this season.

The nutritional status was observed to be better in Idjwi than in Burhinyi, even if anthropometric indices were at the edge of pathological values [28]. Given the persistently high cyanide exposure noticed, we anticipated that the population in Idjwi would be, in the case of sudden nutritional deterioration, at risk of developing konzo. In this study, protein and album serum levels tended to be lower in the DS than in the RS (although significance was not reached in Idjwi), further confirming previous observations. On the other hand, in the case that the nutritional deterioration trend persists or worsens, the contribution of cassava toxicity to the endemic goiter would decrease despite the absence of any preventive or therapeutic intervention, owing to the inability to engage the SCN-related detoxification pathway competing with iodine thyroid uptake [52]. Therefore, the unexpected reduction of endemic goiter should prompt careful assessment of the nutritional level in order to appropriately evaluate and prevent the risk of konzo. 


\section{Conclusions and Limitations}

In conclusion, our results show that seasonal variation differently affected the cyanide content in cassava flour, the nutritional status, and the uSCN levels. (1) The cyanide content in cassava flour increased during the DS, most probably due to the more important consumption of toxic bitter (and to a lesser extent sweet) cassava products, as well as shortening or skipping heap fermentation during cassava processing. (2) Of notice, the traditional processing methods (maintained during the RS), regardless of differences between Burhinyi and Idjwi, were effective enough to reach safe cyanide levels in cassava flour. Thus, adherence to the traditional processing method (in particular, a sufficiently long heap fermentation) should ensure the safe consumption of cassava. (3) On the other hand, seasons did not have impact on uSCN levels (which remained equally higher in both areas and periods) but influenced the nutritional level solely (a rapid nutritional deterioration was restrictively observed in Burhinyi during the DS, further suggesting a role in the occurrence of konzo in accordance with our previous assumption).

Overall, this study further reinforces the new paradigm of a hierarchy between the two konzo risk factors, with a first prerequisite for malnutrition existence and additional cassava-related cyanide exposure. Here, we add in the role of seasonal variation of both factors, with acute nutritional deterioration and higher cyanide intoxication during the DS. It finally appears, from this conceptual frame, that the population of Idjwi is not far from being highly at risk of developing konzo (in case of further worsening of its nutritional status).

Despite these interesting findings, and careful and rigorous methodology, the results of this study should be taken with great caution, as the final small sample, especially in Idjwi, might have influenced our observed correlations or differences. They need further confirmation in larger populations.

Supplementary Materials: The following supporting information can be downloaded at: https: / / www.mdpi.com/article/10.3390/pr10020337/s1, Table S1: Comparison between final study population and excluded participants.

Author Contributions: Conceptualization, M.B. and J.N.C.; methodology, M.B. and J.N.C.; validation, J.-M.R. and J.N.C.; formal analysis, M.B.; investigation, M.B., F.N., W.L.S. and C.M.A.; resources, M.B., J.M.B., A.N., P.C., J.-M.R. and J.N.C.; data curation, M.B. and W.L.S.; writing-original draft preparation, M.B., C.M. and J.N.C.; writing-review and editing, M.B., C.M., F.N., W.L.S., C.M.A., S.M.L., J.M.B., A.N., P.C., G.B.M., J.-M.R. and J.N.C.; visualization, M.B. and C.M.; supervision, J.-M.R. and J.N.C.; project administration, G.B.M., J.-M.R. and J.N.C.; funding acquisition, M.B., J.-M.R. and J.N.C. All authors have read and agreed to the published version of the manuscript.

Funding: This research was funded by the VLIR-UOS Team Project 2017, Reference number: CD2017TE A439A104.

Institutional Review Board Statement: This study was conducted in accordance with the Declaration of Helsinki, and was approved by the ethical committee of the Université Catholique de Bukavu (ethical approval code: UCB/CIE/NC/001/2017), by the Medical Ethics Committee (CME) of the Hasselt University (approval code: CME2017/764), and by the Social and Societal Ethics Committee (SMEC) of the Hasselt University (approval code: REC/SMEC/VRAI/178/104).

Informed Consent Statement: Informed consent was obtained from all adult subjects involved in the study, prior to enrolment. For those under the age of 18 , the consent was obtained from parents or legal tutors.

Data Availability Statement: The data presented in this study are available on request from the corresponding author.

Acknowledgments: We are grateful to the "Hôpital Provincial Général de Référence de Bukavu" (HPGRB) and the "Bureau Diocésain des Euvres Médicales" (BDOM) for their logistic facilitations, which significantly eased our field investigations. 
Conflicts of Interest: The authors declare no conflict of interest. The funders had no role in the design of the study; in the collection, analyses, or interpretation of data; in the writing of the manuscript, or in the decision to publish the results.

\section{References}

1. Mbanjo, E.G.N.; Rabbi, I.Y.; Ferguson, M.E.; Kayondo, S.I.; Eng, N.H.; Tripathi, L.; Kulakow, P.; Egesi, C. Technological Innovations for Improving Cassava Production in Sub-Saharan Africa. Front. Genet. 2021, 11, 623736. [CrossRef] [PubMed]

2. Sayre, R.; Beeching, J.R.; Cahoon, E.B.; Egesi, C.; Fauquet, C.; Fellman, J.; Fregene, M.; Gruissem, W.; Mallowa, S.; Manary, M.; et al. The BioCassava plus program: Biofortification of cassava for sub-Saharan Africa. Annu. Rev. Plant Biol. 2011, 62, $251-272$. [CrossRef] [PubMed]

3. Food and Agriculture Organization of the United Nations FAOSTAT. Available online: http://www.fao.org/faostat/en/\#data (accessed on 22 November 2019).

4. Bradbury, J.H.; Denton, I.C. Mild method for removal of cyanogens from cassava leaves with retention of vitamins and protein. Food Chem. 2014, 158, 417-420. [CrossRef] [PubMed]

5. Mcmahon, J.M.; White, W.L.B.; Say, R.T. Cyanogenesis in cassava (Manihot esculenta Crantz). J. Exp. Bot. 1995, 46, 731-741. [CrossRef]

6. Montagnac, J.A.; Davis, C.R.; Tanumihardjo, S.A. Nutritional value of cassava for use as a staple food and recent advances for improvement. Compr. Rev. Food Sci. Food Saf. 2009, 8, 181-194. [CrossRef] [PubMed]

7. Montagnac, J.A.; Davis, C.R.; Tanumihardjo, S.A. Processing techniques to reduce toxicity and antinutrients of Cassava for use as a staple food. Compr. Rev. Food Sci. Food Saf. 2009, 8, 17-27. [CrossRef]

8. Imakumbili, M.L.E.; Semu, E.; Semoka, J.M.R.; Abass, A.; Mkamilo, G. Farmers' perceptions on the causes of cassava root bitterness: A case of konzo-affected mtwara region, Tanzania. PLoS ONE 2019, 14, 1-14. [CrossRef] [PubMed]

9. Santisopasri, V.; Kurotjanawong, K.; Chotineeranat, S.; Piyachomkwan, K.; Sriroth, K.; Oates, C.G. Impact of water stress on yield and quality of cassava starch. Ind. Crops Prod. 2001, 13, 115-129. [CrossRef]

10. Kimani, S.T. Neurotoxicity of Cassava Cyanogens in Rodents and Non-Human Primates. Ph.D. Thesis, University of Nairobi, Nairobi, Kenya, 2011.

11. Teles, F.F.F. Chronic poisoning by hydrogen cyanide in cassava and its prevention in Africa and Latin America. Food Nutr. Bull. 2002, 23, 407-412. [CrossRef]

12. Ceballos, H.; Iglesias, C.A.; Pérez, J.C.; Dixon, A.G.O. Cassava breeding: Opportunities and challenges. Plant Mol. Biol. 2004, 56, 503-516. [CrossRef]

13. Padmaja, G. Cyanide Detoxification in Cassava for Food and Feed Uses. Crit. Rev. Food Sci. Nutr. 1995, 35, 299-339. [CrossRef]

14. Szabo, E.A.; Jansson, E.; Miles, D.; Hambridge, T.; Stanley, G.; Baines, J.; Brent, P. Responding to Incidents of Low Level Chemical Contamination in Food, 1st ed.; Elsevier Inc.: Amsterdam, The Netherlands, 2010; ISBN 9780123748454.

15. Joint FAO/WHO Food Standards Programme. Codex Alimentarius Commission Codex Committee on Contaminants in Foods; Third Session. Discussion Paper on Cyanogenic Glycosides; Joint FAO/WHO Expert Committee on Food Additives: Rome, Italy, 2009.

16. Adamolekun, B. Neurological disorders associated with cassava diet: A review of putative etiological mechanisms. Metab. Brain Dis. 2011, 26, 79-85. [CrossRef]

17. Banea, J.P.; Poulter, N.H.; Rosling, H. Shortcuts in cassava processing and risk of dietary cyanide exposure in Zaire. Food Nutr. Bull. 1992, 14, 137-143. [CrossRef]

18. Tylleskar, T.; Banea, M.; Bikangi, N.; Fresco, L.; Persson, L.A.; Rosling, H. Epidemiological Evidence from Zaire for a Dietary Etiology of Konzo, an Upper Motor-Neuron Disease. Bull. World Health Organ. 1991, 69, 581-589. [PubMed]

19. Essers, A.J.A.; Alsen, P.; Rosling, H. Insufficient processing of cassava induced acute intoxications and the paralytic disease konzo in a rural area of mozambique. Ecol. Food Nutr. 1992, 27, 17-27. [CrossRef]

20. Baguma, M.; Nzabara, F.; Balemba, G.M.; Malembaka, E.B.; Migabo, C.; Mudumbi, G.; Bito, V.; Cliff, J.; Rigo, J.-M.; Chabwine, J.N. Konzo risk factors, determinants and etiopathogenesis: What is new? A systematic review. Neurotoxicology 2021, 85, 54-67. [CrossRef] [PubMed]

21. Ermans, A.M.; Delange, F.; Van der Velden, M.; Kinthaert, J. Goitrogenic action of cyanogenic glucosides present in cassava: A possible etiologic factor of endemic goiter in the Idjwi island. Acta Endocrinol. Suppl. 1973, 179, 31.

22. Alakali, A.J.S.; Ismaila, A.R.; Atume, T.G. Effect of Local Processing Techniques on the Nutrients and Anti-Nutrients Content of Bitter Cassava (Manihot Esculenta Crantz). Am. J. Food Sci. Technol. 2016, 10, 46049.

23. Banea, J.P.; Bradbury, J.H.; Mandombi, C.; Nahimana, D.; Denton, I.C.; Kuwa, N.; Tshala Katumbay, D. Effectiveness of wetting method for control of konzo and reduction of cyanide poisoning by removal of cyanogens from cassava flour. Food Nutr. Bull. 2014, 35, 28-32. [CrossRef]

24. World Health Organization. Konzo-A distinct type of upper motoneuron disease. Wkly. Epidemiol. Rec. 1996, 71, 225-228.

25. Kashala-Abotnes, E.; Okitundu, D.; Mumba, D.; Boivin, M.J.; Tylleskär, T.; Tshala-Katumbay, D. Konzo: A distinct neurological disease associated with food (cassava) cyanogenic poisoning. Brain Res. Bull. 2018, 145, 87-91. [CrossRef]

26. Anonymous. Konzo Count. CCDN News 2005, 6, 3. 
27. Chabwine, J.; Masheka, C.; Balol'ebwami, Z.; Maheshe, B.; Balegamire, S.; Rutega, B.; Wa Lola, M.; Mutendela, K.; Bonnet, M.-J.; Shangalume, O.; et al. Appearance of konzo in South-Kivu, a wartorn area in the Democratic Republic of Congo. Food Chem. Toxicol. 2011, 49, 644-649. [CrossRef]

28. Baguma, M.; Malembaka, E.B.; Bahizire, E.; Mudumbi, G.Z.; Shamamba, D.B.; Matabaro, A.-N.; Rigo, J.-M.; Njamnshi, A.K.; Chabwine, J.N. Revisiting Konzo Risk Factors in Three Areas Differently Affected by Spastic Paraparesis in Eastern Democratic Republic of the Congo Discloses a Prominent Role of the Nutritional Status-A Comparative Cross-Sectional Study. Nutrients 2021, 13, 2628. [CrossRef]

29. John Arnfield, A. Köppen Climate Classification. Available online: https://www.britannica.com/science/Koppen-climateclassification\%0A (accessed on 22 November 2020).

30. Chen, D.; Chen, H.W. Using the Köppen classification to quantify climate variation and change: An example for 1901-2010. Environ. Dev. 2013, 6, 69-79. [CrossRef]

31. Delange, F.; Ermans, A.M.; Vis, H.L.; Stanbury, J.B. Endemic cretinism in Idjwi Island (Kivu Lake, Republic of the Congo). J. Clin. Endocrinol. Metab. 1972, 34, 1059-1066. [CrossRef]

32. UCL_LTAP. Thiocyanates: Urine. Available online: https://www.toxi.ucl.ac.be/documents/thiocyanate_u.htm (accessed on 29 September 2018).

33. Banea, J.P.; Bradbury, J.H.; Mandombi, C.; Nahimana, D.; Denton, I.C.; Kuwa, N.; Tshala Katumbay, D. Control of konzo by detoxification of cassava flour in three villages in the Democratic Republic of Congo. Food Chem. Toxicol. 2013, 60, 506-513. [CrossRef] [PubMed]

34. Bumoko, G.M.; Sombo, M.T.; Okitundu, L.D.; Mumba, D.N.; Kazadi, K.T.; Tamfum-Muyembe, J.J.; Lasarev, M.R.; Boivin, M.J.; Banea, J.P.; Tshala-Katumbay, D.D. Determinants of cognitive performance in children relying on cyanogenic cassava as staple food. Metab. Brain Dis. 2014, 29, 359-366. [CrossRef] [PubMed]

35. Nhassico, D.; Bradbury, J.H.; Cliff, J.; Majonda, R.; Cuambe, C.; Denton, I.C.; Foster, M.P.; Martins, A.; Cumbane, A.; Sitoe, L.; et al. Use of the wetting method on cassava flour in three konzo villages in Mozambique reduces cyanide intake and may prevent konzo in future droughts. Food Sci. Nutr. 2015, 4, 555-561. [CrossRef]

36. Flahaut, M. Le Cyanure dans L'histoire et Intoxications Actuelles. Médecine Humaine et Pathologie. Master's Thesis, Université de Bordeaux 2, Bordeaux France, 2015; p. 109.

37. De-The, G.; Giordano, C.; Gassain, A.; Howlett, W.; Sonan, T.; Akani, F.; Rosling, H.; Carton, H.; Mouanga, Y.; Caudie, C.; et al. Human retroviruses HTLV-I, HIV-1, and HIV-2 and neurological diseases in some equatorial areas of Africa. J. Acquir. Immune Defic. Syndr. 1989, 2, 550-556.

38. Bradbury, M.G.; Egan, S.V.; Bradbury, J.H. Picrate paper kits for determination of total cyanogens in cassava roots and all forms of cyanogens in cassava products. J. Sci. Food Agric. 1999, 79, 593-601. [CrossRef]

39. Haque, M.R.; Bradbury, J.H. Simple method for determination of thiocyanate in urine. Clin. Chem. 1999, 45, 1459-1464. [CrossRef]

40. Mlingi, N.V.; Assey, V.D.; Swai, A.B.M.; Mclarty, D.G.; Karlen, H.; Rosling, H. Determinants of cyanide exposure from cassava in a konzo-affected population in northern Tanzania. Int. J. Food Sci. Nutr. 1993, 44, 137-144. [CrossRef]

41. WorldData.info Climate of South Kivu (Democratic Republic of the Congo). Available online: https://www.worlddata.info/ africa/congo-kinshasa/climate-south-kivu.php (accessed on 10 November 2021).

42. Essers, A.J.A.; Van der Grift, R.M.; Voragen, A.G.J. Cyanogen removal from cassava roots during. Food Chem. 1996, 55, 319-325. [CrossRef]

43. Nambisan, B.; Sundaresan, S. Effect of processing on the cyanoglucoside content of cassava. J. Sci. Food Agric. 1985, 36, 1197-1203. [CrossRef]

44. Cumbana, A.; Mirione, E.; Cliff, J.; Bradbury, J.H. Reduction of cyanide content of cassava flour in Mozambique by the wetting method. Food Chem. 2007, 101, 894-897. [CrossRef]

45. Bradbury, J.H.; Cliff, J.; Denton, I.C. Uptake of wetting method in Africa to reduce cyanide poisoning and konzo from cassava Food Chem. Toxicol. 2011, 49, 539-542. [CrossRef]

46. Nambisan, B. Evaluation of the Effect of Various Processing Techniques on Cyanogen Content Reduction in Cassava. Acta Hortic. 1994, 375, 193-202. [CrossRef]

47. Banea, J.P.; Tylleskar, T.; Gitebo, N.; Matadi, N.; Gebre-Medhin, M.; Rosling, H. Geographical and seasonal association between linamarin and cyanide exposure from cassava and the upper motor neurone disease konzo in former Zaire. Trop. Med. Int. Health 1997, 2, 1143-1151. [CrossRef]

48. Cardoso, A.P.; Mirione, E.; Ernesto, M.; Massaza, F.; Cliff, J.; Haque, M.R.; Bradbury, J.H. Processing of cassava roots to remove cyanogens. J. Food Compos. Anal. 2005, 18, 451-460. [CrossRef]

49. Ginting, E.; Widodo, Y. Cyanide Reduction in Cassava Root Products Through Processing and Selection of Cultivars in Relation to Food Safety. Bul. Palawija 2013, 25, 25-36. [CrossRef]

50. Banea, J.P.; Bradbury, J.H.; Mandombi, C.; Nahimana, D.; Denton, I.C.; Foster, M.P.; Kuwa, N.; Tshala Katumbay, D. Konzo prevention in six villages in the DRC and the dependence of konzo prevalence on cyanide intake and malnutrition. Toxicol. Rep. 2015, 2, 609-616. [CrossRef] [PubMed] 
51. Banea, J.P.; Bikangi, N.; Nahimana, G.; Nunga, M.; Tylleskar, T.; Rosling, H. High prevalence of konzo associated with a food shortage crisis in the Bandundu region of zaire. Ann. Soc. Belg. Med. Trop. 1992, 72, 295-309. [PubMed]

52. Chandra, A.K. Goitrogen in Food: Cyanogenic and Flavonoids Containing Plant Foods in the Development of Goiter. In Bioactive Foods in Promoting Health; Watson, R., Preedy, V., Eds.; Academic Press: San Diego, CA, USA, 2010; pp. $691-716$. ISBN 978-0-12-374628-3. 